\title{
EMBODIED IMPRESSION FORMATION: SOCIAL JUDGMENTS AND MOTOR CUES TO APPROACH AND AVOIDANCE
}

\author{
Michael L. Slepian \\ Tufts University \\ Steven G. Young \\ Fairleigh Dickinson University \\ Nicholas O. Rule \\ University of Toronto \\ Max Weisbuch \\ University of Denver \\ Nalini Ambady \\ Stanford University
}

\begin{abstract}
Motor movements that embody approach and avoidance shape individuals' affective and evaluative responses to objects. In two studies we investigate how approach and avoidance impact participants' judgments of ecologically valid targets: other humans. One trait relevant to the approach or avoidance of other humans is trustworthiness. Trustworthy people can be safely approached, and untrustworthy people should be avoided. We examined whether arm contractions of approach and avoidance enhanced or diminished trust toward others, respectively. Perceived trustworthiness, relative to untrustworthiness, potentiated arm flexion (approach; Study 1). Conversely, arm flexion relative to extension led to increased perceptions of trust (Study 2). Thus, beyond motivational, cognitive, and emotional processes, embodied cues impact impression formation.
\end{abstract}

Approach toward positive stimuli and avoidance of negative stimuli are fundamental building blocks of behavior (Elliot, 2006; Hull, 1943; Lang, Bradley, \& Cuthbert, 1990; Murray, 1938). Interestingly, approach and avoidance behaviors are not only functional reactions to positive or negative stimuli, but can also shape per-

This research was supported in part by National Science Foundation Grant BCS-0435547 to Nalini Ambady and by a National Science Foundation Graduate Research Fellowship to M.L.S.

Correspondence concerning this article should be addressed to Michael L. Slepian, Department of Psychology, 490 Boston Ave., Medford, MA 02155. E-mail: michael.slepian@tufts.edu. 
ceivers' affective and evaluative responses to objects. For instance, in one study, participants who viewed Chinese ideographs during arm flexion (pulling upward on a table) rated them as more pleasant than did participants who viewed the same ideographs during arm extension (pressing downward on a table; Cacioppo, Priester, \& Bernston, 1993). Follow-up research replicated this effect with letter strings (Priester, Cacioppo, \& Petty, 1996) and consumer products (Förster, 2004). Such findings were explained as resulting from the link between bodily motions associated with approach and avoidance and the evaluative consequences of such actions. The muscles used during arm flexion overlap with those used when pulling something toward oneself (i.e., approach), whereas the muscles used during arm extension overlap with those used when pushing something away from oneself (i.e., avoidance). These data suggest that motor or proprioceptive processes play a role in attitude development toward otherwise neutral targets.

We extended this work to the domain of social judgment. People are continuously forming impressions of others during everyday life, and such impression formation occurs spontaneously and immediately (Jones \& Harris, 1967; Skowronski, Carlston, Mae, \& Crawford, 1998; Uleman, Newman, \& Moskowitz, 1996). Research has uncovered the many cognitive, motivational, and emotional determinants of impression formation (for reviews see Brewer, 1988; Fiske \& Neuberg, 1990; Hamilton \& Sherman, 1996; Macrae \& Bodenhausen, 2000). Yet, from a grounded cognition perspective (Barsalou, 2008), social cognition should also consist of modality-specific processes, such as motor, visual, auditory, tactile, and olfactory sensory information (see Slepian, Weisbuch, Rule, \& Ambady, 2011).

A grounded cognition account of impression formation thus suggests that sensorimotor processes should be basic to social judgments. As humans are a fundamentally social species, they are highly dependent on one another. Thus, throughout humans' evolutionary past, successfully approaching friends and avoiding foes was a critical task (Kenrick \& Shiota, 2008). Indeed, previous work has demonstrated that people are quicker to avoid negatively valenced groups such as outgroups and people with AIDS (Neumann, Hülsenbeck, \& Seibt, 2004; Paladino \& Castelli, 2008), and repeated training to approach an outgroup can lead to enhanced positivity toward them (Kawakami, Phills, Steele, \& Dovidio, 2007). In short, exposure to others influences approach/avoidance tendencies. Given that the fundamental behaviors of approach and avoidance are relevant to impression formation, these motor actions should impact concrete and distinct judgments of others.

For example, discrete dimensions such as warmth and competence have been implicated as core factors in person perception (Asch, 1946; Fiske, Cuddy, \& Glick, 2007; Rosenberg, Nelson, \& Vivekananthan, 1968). These two factors underlie a variety of impressions which are drawn spontaneously and often accurately (Albright, Kenny, \& Malloy, 1988; Ambady \& Rosenthal, 1992; Funder \& Colvin, 1991; Skowronski et al., 1998; Uleman et al., 1996). An additional core domain of person perception with clear approach/avoidance implications is the degree to which another person can be trusted (Cosmides \& Tooby, 1992; Ekman, 2003; Krumhuber et al., 2007). A representation of a trustworthy person may include the motor processes that occur during approach, and a representation of an untrustworthy person may include the motor processes that occur during avoidance. Thus, the domain of trustworthiness represents one dimension of impression formation that might be influenced by approach and avoidance. If so, then the perception of a trustworthy individual should potentiate approach, whereas the perception of 
an untrustworthy individual should potentiate avoidance (Study 1). Conversely, providing participants with motor cues of approach (such as arm flexion) should increase judgments of trustworthiness, and providing motor cues of avoidance (such as arm extension) should increase judgments of untrustworthiness (Study 2). By investigating how embodied approach and avoidance reciprocally influence social judgments of trust, we aim to provide a more comprehensive account of the relationship between approach and avoidance behaviors and impression formation.

\section{STUDY 1}

If representations of trustworthy and untrustworthy individuals include motor activity of approach and avoidance, respectively, then perceived trustworthiness, relative to untrustworthiness, should potentiate approach rather than avoidance. Previous research supports this possibility. For example, participants' automatic evaluations of words facilitate congruent behavioral responses, such that negative words are avoided quickly whereas positive words are approached quickly (Chen \& Bargh, 1999). In the current study, we investigated whether social targets that varied in perceived trustworthiness might similarly potentiate action. Participants viewed novel faces perceived as trustworthy or untrustworthy and responded with either the push (avoidance) or pull (approach) of a joystick. We expected that the perception of a trustworthy face would potentiate an approach response, whereas the perception of an untrustworthy face would potentiate an avoidance response.

\section{METHOD}

Participants. Sixty-three undergraduates (58\% female) from a private university in the United States participated in partial fulfillment of a course requirement.

Experimental Stimuli. Twenty grayscale images of male faces with neutral expressions, sized at $300 \times 300$ pixels (presented on a $1024 \times 768$ pixel computer monitor), served as our experimental stimuli. The images were controlled for distance, angle, and luminosity. These faces were previously rated on trustworthiness as part of a larger set of faces by 20 undergraduates, who rated each face on a scale ranging from 1 (Not at all trustworthy) to 7 (Very trustworthy). Ten of these faces were previously rated as untrustworthy $(M=3.09, S D=0.29)$ and the other ten were rated as trustworthy $(M=4.18, S D=0.18)$. Although the two sets significantly differed in terms of trustworthiness, $t(18)=10.14, p<.0001, r=.92$, ratings from the same participants showed that they did not differ along other influential variables, such as facial attractiveness, $t(18)=1.26, p=.22$. Additionally, a set of 20 grayscale images of houses served as control stimuli. These images were also $300 \times 300$ pixels in size and, to enhance similarity to the faces, were cropped into an oval shape.

Procedure. Participants were seated at a computer and informed that the study was a test of their reaction time. They performed an Approach-Avoidance Task (AAT; Rinck \& Becker, 2007) composed of pictures of houses and trustworthy and untrustworthy faces. In one block, participants were instructed to pull a joystick toward them (approach) when a face appeared on the computer screen and to push 
the joystick away from them (avoidance) when a house appeared onscreen. In another block, these instructions were reversed (i.e., participants were instructed to push for faces and pull for houses). The order of these blocks was counterbalanced across participants. No mention was made that the faces varied along the dimension of perceived trustworthiness. To eliminate ambiguity about the meaning of pushing versus pulling the joystick (see Eder \& Rothermund, 2008; Krieglmeyer, Deutsch, De Houwer, \& De Raedt, 2010; Markman \& Brendl, 2005; Proctor \& Zhang, 2010), the picture either grew or shrank in size as the joystick was moved. When the joystick was pushed away, the image progressively shrank over the course of a second until reaching $20 \%$ of its original size and then disappeared-providing the illusion of pushing the face/house away. When the joystick was pulled toward the participant, the image progressively grew over the course of a second until reaching $200 \%$ of its original size and then disappeared-providing the illusion of pulling the face/house closer. Each block began with 10 practice trials ( 5 houses and 5 faces neutral in trustworthiness) and continued with 40 additional trials (20 houses, 10 trustworthy faces, and 10 untrustworthy faces), for a total of 100 trials. During debriefing, no participants mentioned an awareness that the faces varied on trustworthiness.

\section{RESULTS AND DISCUSSION}

Eight participants made a substantial number of errors (over $46 \%$ of trials), indicating a failure to follow instructions or confusion about when to push or pull. These participants were excluded from the analysis. Of the remaining participants, incorrect responses were low $(M=2.12 \%, S D=2.38 \%)$. Incorrect responses and response times (RTs) lying 2.5 standard deviations beyond each participant's mean RT were excluded $(8.6 \%)$. After these exclusions, three individuals had mean RTs exceeding the grand mean by more than 2.5 standard deviations; these individuals were also excluded from the analysis. The data were then transformed using the natural logarithm to achieve normality (Shapiro-Wilk's $W=.97, p=.20$ ).

A 2 (joystick-direction) $\times 2$ (face-type) repeated measures analysis of variance (ANOVA) was conducted with RT as the dependent variable. This analysis revealed no main effect of joystick-direction, $F(1,51)<0.01, p=.99$, or face-type, $F(1,51)=1.52, p=.22$, on RT, but did reveal the predicted significant interaction between joystick-direction and face-type, $F(1,51)=4.35, p=.04, r=.28$ (see Figure 1). Participants were quicker to pull (approach) in response to trustworthy faces (untransformed $M=525 \mathrm{~ms}, S D=85$ ) compared to untrustworthy faces (untransformed $M=543 \mathrm{~ms}, S D=101), t(51)=2.21, p=.03, r=.30$. There were no differences, however, in speed of pushing (avoidance) in response to trustworthy faces (untransformed $M=535 \mathrm{~ms}, S D=93$ ) and untrustworthy faces (untransformed $M$ $=531 \mathrm{~ms}, S D=78), t(51)=0.39, p=.70$.

Participants were especially slow to make an approach arm movement toward an untrustworthy, relative to a trustworthy, face. However, participants were not faster to make avoidant arm movements upon the perception of an untrustworthy, relative to a trustworthy, face. This asymmetry may reflect an adaptive strategy wherein it is more advantageous to be cautious in approaching an untrustworthy person than it is detrimental to avoid a trustworthy person (e.g., Haselton \& Funder, 2006). 


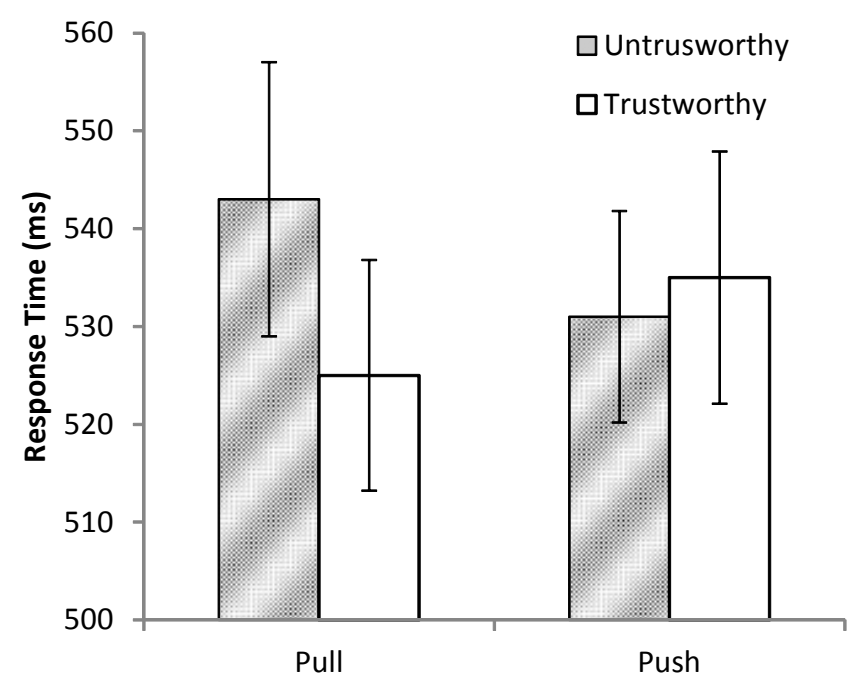

FIGURE 1. Mean RTs in Study 1 to respond to faces.

Approach and avoidance behaviors are not only functional reactions to positive or negative stimuli, but such motions can also shape affective and evaluative responses to objects (e.g., Cacioppo et al., 1993). Thus, in Study 2 we examined whether providing participants with embodied cues to approach and avoidance would influence the impressions they formed of others.

\section{STUDY 2}

Participants were exposed to novel faces perceived as neutral in trustworthiness during arm flexion and extension. Subsequently, they indicated how trustworthy each face was. Judgments of trust imply that a person can be approached, and judgments of distrust imply that a person should be avoided; thus we expected that arm flexion during the perception of novel faces would lead to later judgments of trustworthiness, whereas extension would lead to judgments of untrustworthiness.

\section{METHOD}

Participants. Fifty-five undergraduates (56\% female) from a private university in the United States participated in partial fulfillment of a course requirement.

Experimental Stimuli. Twenty-four targets were selected from the same pool of previously rated photographs as were those in Study 1 . The 24 faces selected were those centered around the mean of the distribution of trustworthiness $(M=3.75, S D$ $=0.24$ ) so as to be as neutral in perceived trustworthiness as possible. We then divided the faces into two sets of 12 faces for assignment to each arm-contraction condition; the two sets of faces did not differ in trustworthiness, $t(22)=0.05, p=.96$.

Procedure. Participants were seated at a computer and informed that the study was investigating the effects of arm tension on impression formation. Participants were exposed to two sets of 12 faces, one during arm extension and one during 
arm flexion. For arm extension, participants were instructed to press the palm of their nondominant hand down flat on top of the computer desk; and, for arm flexion, to press their nondominant palm upward against the underside of the desk. During arm contractions, participants were asked to indicate whether they liked or did not like each face during viewing and provided their responses via key-press. The order of arm-contraction and image presentations was randomized, and facearm-contraction pairings were counterbalanced across participants. A one minute break was provided between the two arm contractions.

After viewing the two sets of faces with each arm contraction, participants relaxed their arms and were given a randomly shuffled stack of 24 cards. Each card was $4^{\prime \prime} \times 4^{\prime \prime}$ and displayed one of the 24 previously presented faces. Participants were instructed to place four faces in each of six categories: extremely untrustworthy, very untrustworthy, untrustworthy, trustworthy, very trustworthy, and extremely trustworthy. These six categories were coded as -3 (extremely untrustworthy) to 3 (extremely trustworthy), following the coding procedure described by Cacioppo and colleagues (1993). Participants were encouraged to spread the cards out on the desk to aid categorization.

Subsequently, participants completed a brief, six-item questionnaire that asked how difficult, uncomfortable, and enjoyable each arm contraction had been, selecting from 1 (Not at all comfortable) to 11 (Extremely comfortable). During debriefing, no participants expressed suspicion that the arm contractions influenced their evaluations of the faces.

\section{RESULTS AND DISCUSSION}

First, we sought to determine that the two arm-contractions were not differently rated by participants in terms of difficulty, comfort, or enjoyment. Indeed, participants did not rate arm flexion differently from arm extension in terms of difficulty, $t(54)=0.71, p=.48$, comfort, $t(54)=0.54, p=.59$, or enjoyment, $t(54)=1.08, p=$ .28. Similar to prior research (Cacioppo et al., 1993), arm movements appeared to influence liking ratings at encoding; there was a trend for faces viewed during arm flexion to concurrently be liked $(M=30 \%, S D=23)$ more than those viewed during arm extension $(M=27 \%, S D=19), t(54)=1.55, p=.13$. To test our primary predictions, we conducted a repeated measures ANCOVA with trustworthy ratings of previously approached and avoided faces as the dependent measures, and with the inclusion of a covariate of previous liking for those faces (percent liked during approach minus percent liked during avoidance). Critically, and as predicted, this analysis revealed that faces viewed during arm flexion (approach) were rated as more trustworthy $(M=0.14, S D=0.42)$ than were faces viewed during arm extension (avoidance; $M=-0.14, S D=0.42$ ), $F(1,53)=4.76, p=.03, r=.29 .{ }^{1}$ Arm contractions had a significant influence upon subsequent judgments of whether faces were trustworthy or untrustworthy. Faces viewed during arm flexion were later rated as trustworthy, whereas faces viewed during arm extension were later rated as untrustworthy. This is noteworthy given that the faces themselves were relatively neutral in trustworthiness and that participants were not aware that

1. Removing the covariate from the analysis results in an identical pattern of means and statistical significance, $F(1,54)=6.03, p=.02, r=.32$. 
they would be evaluating the faces with regard to trustworthiness at a later point. Moreover, these effects were not due to differences in the relative comfort, enjoyment, or difficulty of the two contraction exercises.

Study 2 provides converging evidence for the role of approach and avoidance motor movements in social judgment. In Study 1, trustworthy, relative to untrustworthy, faces potentiated approach. Conversely, in Study 2 faces paired with arm flexion (approach) were later rated as more trustworthy, whereas faces paired with arm extension (avoidance) were later rated as more untrustworthy.

\section{GENERAL DISCUSSION}

Because approach and avoidance are regarded as fundamental dimensions of behavior (Elliot, 2006; Hull, 1943; Lang et al., 1990; Lewin, 1935; Murray, 1938), motor activity consistent with approach and avoidance may exert a profound influence on social judgments. Indeed, in two studies we demonstrated that this was the case in the domain of trustworthiness. Trustworthy, relative to untrustworthy, faces potentiated approach to a greater extent than avoidance (Study 1). The converse was also true: arm contractions of approach and avoidance impacted ratings of trust. That is, arm flexion (approach), relative to arm extension (avoidance), led to increased ratings of trust (Study 2).

The present work expands upon previous research demonstrating the link between approach-avoidance motor action and evaluation by showing that these effects apply to person perception. The complexities of when to approach or avoid another person may be presumed to greatly outweigh the approach/avoidance behavior relevant to inanimate objects. A more thorough understanding of the informational value of approach and avoidance motor behaviors therefore requires the consideration of how such motions affect the perception of social targets. Toward this end, the present work revealed that approach/avoidance behaviors can guide social judgments.

Importantly, with respect to the ecological validity of the current research, motor functions associated with approach and avoidance influenced a fundamental social judgment: the trustworthiness of particular targets. Given the importance of successfully navigating social interactions, such as finding safe and reliable interaction partners (Brewer, 1999; Cosmides, Barrett, \& Tooby, 2010), approaching trustworthy and avoiding untrustworthy individuals is a critical ability. In the current research, we found consistent evidence that the perceived trustworthiness of targets potentiates approach or avoidance behavior, and that approach/avoidance behavior impacts perceived trustworthiness.

Notably, other dimensions of social judgment are likely relevant to approach and avoidance behaviors. For instance, competence- a core dimension of social judgment-would likely influence (and be influenced by) approach and avoidance behavior. The relationship between competence and approach/avoidance behavior is likely more complex, however. One might wish to only approach competent people as these individuals would likely be of great help in the pursuit of one's goals. Yet, approaching an incompetent person could be beneficial as well if one wished to take advantage of that person. We chose trustworthiness as an illustrative example in this work as the relationship between approach and avoidance behaviors and trustworthiness is more direct: It is beneficial to approach trustwor- 
thy and avoid untrustworthy individuals. Future research may wish to examine the influence of motor cues on other trait judgments.

Although past work has demonstrated a bidirectional behavior-evaluation link (Cacioppo et al., 1993; Chen \& Bargh, 1999) to also include social stimuli (Kawakami et al., 2007; Neumann et al., 2004; Paladino \& Castelli, 2008), we present the first evidence that we are aware of demonstrating the influence of approach and avoidance on core aspects of impression formation. In sum, the present work demonstrates that beyond motivational, cognitive, and emotional processes involved in person perception and impression formation, there exists an embodied component as well, which likely influences a range of trait-judgments. Here, trustworthy and untrustworthy faces differentially potentiated approach compared to avoidance, and experiencing momentary motor activity consistent with approach or avoidance influenced perceivers' impressions of trustworthiness.

\section{REFERENCES}

Albright, L., Kenny, D. A., \& Malloy, T. E. (1988). Consensus in personality judgments at zero acquaintance. Journal of Personality and Social Psychology, 55, 387-395.

Ambady, N., \& Rosenthal, R. (1992). Thin slices of expressive behavior as predictors of interpersonal consequences: A meta-analysis. Psychological Bulletin, 111, 256-274.

Asch, S. E. (1946). Forming impressions of personality. Journal of Abnormal and Social Psychology, 41, 258-290.

Barsalou, L. W. (2008). Grounded cognition. Annual Review of Psychology, 59, 617-645.

Brewer, M. B. (1988). A dual process model of impression formation. In T. K. Srull \& R. S. Wyer (Eds.), A dual-process model of impression formation: Advances in social cognition (Vol. 1, pp. 1-36). Hillsdale, NJ: Erlbaum.

Brewer, M. B. (1999). The psychology of prejudice: Ingroup love or outgroup hate? Journal of Social Issues, 55, 429-444.

Cacioppo, J. T., Priester, J. R., \& Berntson, G. G. (1993). Rudimentary determinants of attitudes. II: Arm flexion and extension have differential effects on attitudes. Journal of Personality and Social Psycholo$g y, 65,5-17$.

Chen, M., \& Bargh, J. A. (1999). Nonconscious approach and avoidance behavioral consequences of the automatic evaluation effect. Personality and Social Psychology Bulletin, 25, 215-224.

Cosmides, L., Barrett, H. C., \& Tooby, J. (2010). Adaptive specializations, social ex- change, and the evolution of human intelligence. Proceedings of the National Academy of Sciences, 107, 9007-9014.

Cosmides, L., \& Tooby, J. (1992). Cognitive adaptations for social exchange. In J. Barkow, L. Cosmides, \& J. Tooby (Eds.), The adapted mind (pp. 163-228). New York: Oxford University Press.

Eder, A., \& Rothermund, K. (2008). When do motor behaviors (mis)match affective stimuli? An evaluative coding view of approach and avoidance reactions. Journal of Experimental Psychology: General, 137, 262-281.

Ekman, P. (2003). Darwin, deception, and facial expression. Annals of the New York Academy of Science, 100, 205-221.

Elliot, A. J. (2006). Approach and avoidance motivation. Motivation and Emotion, 30, 111-116.

Fiske, S. T., Cuddy, A. J. C., \& Glick, P. (2007). Universal dimensions of social cognition: Warmth and competence. Trends in Cognitive Sciences, 11, 77-83.

Fiske, S. T., \& Neuberg, S. L. (1990). A continuum model of impression formation from category-based to individuating processes: Influences of information and motivation on attention and interpretation. In M. P. Zanna (Ed.), Advances in experimental social psychology (Vol. 23, pp.1-74). San Diego, CA: Academic.

Förster, J. (2004). How body feedback influences consumers' evaluation of products. Journal of Consumer Psychology, 14, 416-425. 
Funder, D. C., \& Colvin, C. R. (1991). Explorations in behavioral consistency: Properties of persons, situations, and behaviors. Journal of Personality and Social Psychology, 60, 773-794.

Hamilton, D. L., \& Sherman, S. J. (1996). Perceiving persons and groups. Psychological Review, 103, 336-355.

Haselton, M. G., \& Funder, D. (2006). The evolution of accuracy and bias in social judgment. In M. Schaller, D. T. Kenrick, \& J. A. Simpson (Eds.), Evolution and social psychology (pp. 15-37). New York: Psychology Press.

Hull, C. (1943). Principles of behavior. New York: Appleton-Century-Crofts.

Jones, E. E., \& Harris, V. A. (1967). The attribution of attitudes. Journal of Experimental Social Psychology, 3, 1-24.

Kawakami, K., Phills, C. E., Steele, J. R., \& Dovidio, J. F. (2007). (Close) Distance makes the heart grow fonder: Improving implicit racial attitudes and interracial interactions through approach behaviors. Journal of Personality and Social Psychology, 92, 957-971.

Kenrick, D. T., \& Shiota, M. N. (2008). Approach and avoidance motivation(s): An evolutionary perspective. In A. J. Elliot (Ed.), Handbook of approach and avoidance motivation (pp. 273-288). New York: Psychology Press.

Krieglmeyer, R., Deutsch, R., De Houwer, J., \& De Raedt, R. (2010). Being moved: Valence activates approach-avoidance behavior independently of evaluation and approach-avoidance intentions. Psychological Science, 21, 607-613.

Krumhuber, E., Manstead, A. S. R., Kappas, A., Cosker, D., Marshall, D., \& Rosin, P. L. (2007). Facial dynamics as indicators of trustworthiness and cooperative behavior. Emotion, 7, 730-735.

Lang, P. J., Bradley, M. M., \& Cuthbert, B. N. (1990). Emotion, attention, and the startle reflex. Psychological Review, 97, 377-395.

Lewin, K. (1935). A dynamic theory of personality. New York: McGraw-Hill.

Macrae, C. N., \& Bodenhausen, G. V. (2000). Social cognition: Thinking categorically about others. Annual Review of Psycholo$g y, 51,93-120$.
Markman, A. B., \& Brendl, C. M. (2005). Constraining theories of embodied cognition. Psychological Science, 16, 6-10.

Murray, H. (1938). Explorations in personality. New York: Oxford University Press.

Neumann, R., Hülsenbeck, K., \& Seibt, B. (2004). Attitudes toward people with AIDS and avoidance behavior: Automatic and reflective bases of behavior. Journal of Experimental Social Psychology, 40, 543-550.

Paladino, P., \& Castelli, L. (2008). On the immediate consequences of intergroup categorization: Activation of approach and avoidance motor behaviour toward ingroup and outgroup members. Personality and Social Psychology Bulletin, 34, 755-768.

Priester, J. R., Cacioppo, J. T., \& Petty, R. E. (1996). The influence of motor processes on attitudes toward novel versus familiar semantic stimuli. Personality and Social Psychology Bulletin, 22, 442-447.

Proctor, R. W., \& Zhang, Y. (2010). "Mother nature doesn't have a bullet with your name on it": Coding with reference to one's name or object location? Journal of Experimental Social Psychology, 46, 336-343.

Rinck, M., \& Becker, E. S. (2007). Approach and avoidance in fear of spiders. Journal of Behavior Therapy and Experimental Psychiatry, 38, 105-120.

Rosenberg, S., Nelson, C., \& Vivekananthan, P. S. (1968). A multidimensional approach to the structure of personality impressions. Journal of Personality and Social Psychology, 9, 283-294.

Skowronski, J. J., Carlston, D. E., Mae, L., \& Crawford, M. T. (1998). Spontaneous trait transference: Communicators take on the qualities they describe in others. Journal of Personality and Social Psycholo$g y, 74,837-848$.

Slepian, M.L., Weisbuch, M., Rule, N.O., \& Ambady, N. (2011). Tough and tender: Embodied categorization of gender. Psychological Science, 22, 26-28.

Uleman, J. S., Newman, L. S., \& Moskowitz, G. B. (1996). People as flexible interpreters: Evidence and issues from spontaneous trait inference. In M. P. Zanna (Ed.), Advances in experimental social psychology (Vol. 28, pp. 211-279). San Diego: Academic. 